\title{
A dimensão cuidadora do trabalho de equipe em saúde e sua contribuição para a odontologia
}

The health team work care dimension and its contribution for dentistry

Michelle Cecille Bandeira Teixeira ${ }^{1}$

\begin{abstract}
This article presents a qualitative study, which analyzes the health work process of a multiprofessional team under the care perspective and its contribution to the daily dentist's activities. The participative observation technique was used with registration in field diary, besides interviews and record of patients. The data interpretation was carried on the approach named "production of sense in the everyday life". The analysis shows a logical way of the teamwork towards care, filling up the dentist's development on the link with the patient and responsibility, influencing aspects of dentistry practices.
\end{abstract}

Key words Multiprofessional team, Dentist, Humanization
Resumo Este artigo apresenta um estudo qualitativo que analisa o processo de trabalho em saúde de uma equipe multiprofissional na perspectiva do cuidado e sua contribuição ao cotidiano do trabalho odontológico. Utilizou-se a técnica de observação participante, com registros em diário de campo, além de entrevistas e análise de prontuários. A abordagem adotada para a interpretação dos dados foi "produção de sentidos no cotidiano". A análise revela uma lógica de trabalho da equipe direcionada para o cuidado, impregnando o desempenho do dentista na produção de vínculo e responsabilização, de modo a influenciar os aspectos da prática odontológica.

Palavras-chave Equipe multiprofissional, Cirurgião-dentista, Humanização

\footnotetext{
1 Programa de Graduação em Odontologia,

Faculdade de Odontologia Universidade Salgado de Oliveira.

Rua Marechal Deodoro 21, Centro, 24030-060,

Niterói RJ.

miccecille@yahoo.com
} 


\section{Introdução}

No percurso do SUS, são muitos os avanços e também os desafios a enfrentar para garantir o direito à saúde. $\mathrm{O}$ acesso do usuário aos bens de saúde e a responsabilização dos profissionais por sua clientela permanecem com graves lacunas. A esse quadro acrescentam-se uma desvalorização dos trabalhadores de saúde, pouca participação na gestão dos serviços e frágil vínculo com os usuários. Chama a atenção o despreparo dos profissionais para lidar com a dimensão subjetiva inerente à prática de saúde. Em correlação a isto, configura-se a existência de modelos de gestão centralizados e verticais, desapropriando o trabalhador de seu próprio processo de trabalho (Brasil1).

Para assegurar o cumprimento do objetivo fundamental de cada organização - produzir saúde, educar e, ao mesmo tempo, estimular os trabalhadores a ampliar sua capacidade de reflexão, co-gestão e, conseqüentemente, de realização profissional e pessoal -, Campos $^{2}$ propõe a busca de um modelo tecnoassistencial comprometido e vinculado com os usuários, que atue em equipes multiprofissionais, operando conhecimentos multidisciplinares.

Werneck \& Ferreira ${ }^{3}$ destacam a necessidade de reformulações no processo de trabalho em saúde bucal, o que ainda representa um desafio para a profissão odontológica. Assim, sustentam que, para as transformações ocorrerem de forma harmônica e sistemática com os interesses dos usuários e dos serviços, faz-se necessária uma adequada conformação das tecnologias dura, leve-dura e leve. De acordo com Merhy \& Onocko 4 , a tecnologia leve compreende as relações do tipo de produção de vínculo, autonomização e acolhimento. Já a leve-dura se caracteriza pelos saberes bem estruturados que operam no processo de trabalho em saúde. E a tecnologia dura refere-se não somente aos equipamentos tecnológicos, tais como máquinas, mas também a normas e estruturas organizacionais. Portanto, Werneck \& Ferreira ${ }^{3}$ enfatizam que, para haver uma mudança efetiva, a odontologia precisa integrar-se com outras áreas do desenvolvimento humano.

É nesse sentido que se justifica o estudo em questão, que tem como objetivo analisar a dimensão do cuidado em uma equipe multiprofissional e sua contribuição para o processo de trabalho odontológico.

\section{Escolhas metodológicas}

Este estudo é parte de uma pesquisa realizada em uma maternidade pública do município do Rio de Janeiro, no período de março a novembro de 2002, em um serviço de atenção interdisciplinar aos recém-nascidos com risco de desenvolvimento. A equipe multiprofissional desse serviço é composta de três pediatras, uma nutricionista, uma enfermeira, duas auxiliares de enfermagem, três terapeutas ocupacionais, três fonoaudiólogas e uma cirurgiã-dentista.

Ao imergir em uma investigação que busca interpretar percepções de trabalhadores em saúde sobre suas ações no campo do seu processo de trabalho, este estudo inscreve-se na linha de pesquisa qualitativa que, de acordo com Minayo ${ }^{5}$, implica levar em conta os sujeitos envolvidos no estudo, sua condição social, suas crenças, valores e significados. Considera ainda que o objeto das ciências da saúde, tal como o das ciências sociais, é complexo, contraditório, inacabado e em permanente transformação.

A técnica de observação participante foi a escolhida para a realização do trabalho de campo. Esta técnica permitiu captar uma variedade de situações ou fenômenos que não poderiam ter sido obtidos por meio de perguntas, uma vez que, observados diretamente na própria realidade, transmitem o que se encontra na tessitura do real, como ressalta Minayo5. O olhar do pesquisador não exclui a sua própria prática como participante da equipe. Em vez disso, as suas interpretações e inferências recaem sobre o próprio processo de trabalho odontológico, transformando e sendo transformado pelas interfaces no interior do trabalho da equipe, quando esta é problematizada na perspectiva da interdisciplinaridade estrutural proposta por Japiassu6, em que as trocas no interior do grupo são recíprocas e o enriquecimento é mútuo.

É neste foco que a dimensão "cuidadora" é analisada como uma importante interface dessa equipe, que a todo o momento influencia o cotidiano da prática do dentista. Portanto, todas as observações expressas foram investigadas, reconhecendo-se a subjetividade e o inter-relacionamento entre os sujeitos como parte do fenômeno em estudo.

Através de um diário de campo foram registradas informações sobre conversas, comportamento interprofissional e situações ocorridas no dia-a-dia do trabalho em equipe e em reuniões.

Foram realizadas também entrevistas abertas gravadas em fitas cassete, com profissionais 
e mães de pacientes. Ao todo foram 13 entrevistas -8 com profissionais ( $\mathrm{P} 1, \mathrm{P} 2, \mathrm{P} 3, \mathrm{P} 4, \mathrm{P} 5, \mathrm{P} 6$, P7, P8), sendo no mínimo um de cada profissão, e 5 com mães (M1, M2, M3, M4, M5), que tinham seus filhos acompanhados há pelo menos três anos. Minayo ${ }^{5}$ assinala que, em uma abordagem qualitativa, o critério de amostragem não é numérico. Preocupa-se menos com a generalização e mais com o aprofundamento e a abrangência da compreensão, seja de um grupo social, de uma organização, de uma instituição, de uma política ou de uma representação.

Utilizaram-se também registros de prontuários e do livro de atas das reuniões, que continham anotações desde a primeira reunião da equipe, em outubro de 2002, até o período final deste estudo.

A análise dos dados foi feita durante todos os momentos da pesquisa. Para a análise das práticas discursivas, adotou-se a abordagem teórico-metodológica de Spink 7 , denominada “produção de sentidos no cotidiano”. Este método privilegia as práticas discursivas e remetese aos momentos de ressignificações, de rupturas, de produção de sentidos, considerando as maneiras pelas quais as pessoas se posicionam nas relações sociais cotidianas.

\section{O trabalho em saúde no cotidiano da equipe}

A equipe multiprofissional escolheu iniciar o trabalho atendendo cada paciente em uma mesma sala. A gente começou assim: uma equipe inexperiente [...] a gente fez um trabalho de união mesmo, atendiamos junto, na mesma sala, médico, terapeuta, fono... [...] todos os profissionais com cada criança. [...] (P8)

Essa foi uma experiência de aprendizado, na qual os profissionais tiveram a oportunidade de conhecer as potencialidades do trabalho das suas diferentes áreas. Isto garantiu uma primeira forma de articulação dos saberes, para aprender e perceber o que interessava mais em cada área, qual a intercessão entre as ações específicas e, então, promover uma interação e construir um trabalho em equipe.

Nesse primeiro momento, os profissionais buscaram maneiras diferentes de atuação em saúde.Havia uma autonomia garantida por uma organização horizontal do serviço, que trouxe a possibilidade de revelar trabalhadores da saúde com iniciativa, comprometidos com a produção de suas ações.
Consoante com a conquista do grupo enfocado, Campos ${ }^{8}$ propõe reaproximar os profissionais do resultado de seu trabalho, por intermédio do envolvimento de todos os participantes de uma equipe com o funcionamento de um programa dentro da sua instituição. Desta forma, o profissional ganha estímulo e responsabilidade pelo objeto final de sua intervenção.

Ao participarem na formulação de programas nos quais estão inseridos, os trabalhadores da saúde deixam de ser meros operadores de ações verticalmente estabelecidas. A vantagem maior disso é a possibilidade de os profissionais diagnosticarem e discutirem problemas que seriam indetectáveis por uma visão externa. Muitas questões que surgem no cotidiano do trabalho não aparecem nas estatísticas, mas são percebidas e problematizadas pelos próprios profissionais que estão atuando.

[depois] a gente optou por atender separado porque ficava uma bagunça na consulta, um falava, o outro falava [...]É interessante, só que as orientações dadas pra mãe eram dadas junto, ficava muita coisa de uma vez só. (P2)

Trabalhar todos juntos na mesma sala pode ser perfeito para a interação da equipe, mas cria obstáculos na interação com o paciente, demonstrando que a maior dificuldade dessa forma de trabalho ocorria provavelmente na dimensão da relação profissional/paciente. Enquanto o profissional precisa estabelecer uma relação de diálogo e proximidade, o paciente precisa se sentir à vontade e tranqüilo para buscar cumplicidade e confiança no profissional.

É nesse sentido que Merhy et al. 4 usam a expressão "trabalho vivo em ato" [grifo nosso], que é quando ocorre o encontro com o usuário final, momento em que se revelam alguns componentes vitais da tecnologia leve no trabalho em saúde.

[...] por isso uma integração que eles [pacientes] têm com os profissionais. Eu acho que têm uma boa interação. [...] Porque eles sabem que vão chegar lá dentro e vão ser bem atendidos. Não vai ser aquele profissional que está à distância. É um profissional que escuta. Eu acho que o mais importante é aquele profissional que escuta, não escuta só a queixa, escuta o geral do paciente. [...] quando você tem interação com as pessoas, você consegue compreendê-las e deixá-las à vontade. [...] Porque se a gente respeitar os pacientes, automaticamente eles vão nos respeitar. Então, a troca de valores é muito importante. (P5)

Toda a prática em saúde está permeada por uma dimensão "cuidadora”, que visa produzir 
processos de falas e escutas, relações intercessoras com o mundo subjetivo do usuário - como ele constrói suas necessidades de saúde -, relações de acolhimento e vínculo, posicionamento ético, articulação de saberes para compor projetos terapêuticos, etc. (Merhy $\left.{ }^{9}\right)$.

A dimensão "cuidadora" dessa equipe é constante no seu cotidiano, e a formação do vínculo com os pacientes é uma manifestação presente disso. $\mathrm{O}$ vínculo entre trabalhador (ou equipe ou instituição) e usuário é interpretado ou expresso de diferentes formas, tanto pelo trabalhador quanto pelo usuário em saúde.

$\mathrm{O}$ atendimento pelo mesmo profissional é um fator que alimenta o vínculo, pois o paciente vai ao encontro de um profissional que ele já conhece. Se você tiver um bom tempo dentro do mesmo setor, ela [mãe] vai acabar se acostumando com você, até mesmo se abrindo mais. (P3) Esta constância é importante por produzir no profissional a responsabilização pelo cuidado do seu paciente. Entretanto, a criação do vínculo depende ainda mais da forma como o profissional conduz o encontro, como enfoca a relação com o paciente.

Eu acho que o vínculo a gente faz, a gente que dá [...] faz o paciente ter vínculo com a gente. É o profissional que faz isso. À medida que você dá apoio para aquela família, você está lá pra atendê-lo [o paciente] com respeito. Você ouve o que ele fala. Então você faz com que o paciente tenha vínculo. ( $\mathrm{P} 2)$

A base está no olhar de responsabilização do profissional pelo cuidado do usuário, o que exige mais que um interrogatório de anamnese centrado no procedimento. Exige um diálogo que produz momentos de fala e escuta, em que o paciente passa a se sentir confiante e reconhece aquele profissional como uma referência de cuidado. Tal conduta ainda é pouco perceptível na prática odontológica. Destacamos o estudo de Aquino et al.10: ao avaliar a prática do diálogo entre o paciente e o profissional de odontologia em formação, esse trabalho concluiu que ela é pouco valorizada, restringindo-se principalmente a dados anamnésicos.

Tal constatação torna-se ainda mais relevante na medida em que Moraes \& Ongaro11 afirmam que o resultado de um processo terapêutico é decididamente influenciado pela qualidade da interação profissional-paciente, mesmo quando se dispõe de diagnóstico e prescrição de tratamento competente, confirmando que o trabalho em saúde torna-se vazio quando isento de suas dimensões social e humana.
É enfatizada a importância de se estabelecer um vínculo com a criança. Recebê-la com carinho e com respeito - Trata todo mundo igual, né, porque às vezes é difícil de encontrar um lugar que trata todo mundo igual (M4) - é essencial para a relação com a família desta criança. [...] o vínculo da gente com a criança também é importante. O carinho que a gente tem pelas crianças é importante. Porque a mãe vê isso. (P4)

A interação da equipe, criando mecanismos de acolhimento, é uma possibilidade de buscar a melhor forma de não deixar o paciente se sentir "um estranho no ninho":

Existe um vínculo afetivo. Eles gostam da gente, a gente procura ser sempre o mesmo profissional a atender [...] mesmo que seja outro profissional atendendo, a coisa é feita de tal forma que a pessoa não se sinta um "estranho no ninho" [...]. (P1)

O profissional de saúde compromissado com o usuário passa a ter um olhar para além do corpo que está à sua frente, palpável, visível ou diagnosticável através do estetoscópio, do exame clínico. $\mathrm{O}$ olhar deve se dirigir para a produção de cuidado daquele sujeito. Portanto, o profissional que tece o ato de cuidar no seu cotidiano está sempre ampliando suas ações.

Hoje eu atendi uma mãe que estava com duas bolas de pus na garganta. Numa "situação comum”, o que teria acontecido? Primeiro, ela não iria nem ter abertura de dizer o que estava sentindo. Pra começar, ela não ia nem ser besta de falar dela na consulta do filho. Então ela sentou e falou do filho e tal. Aí eu comentei: "Você está um pouquinho rouca." Ela falou: "É, eu estou com uma dor de garganta!" [...] e quando acabei a consulta do filho eu disse: "Agora deixa eu examinar essa garganta." (P1)

Essa "situação comum" refere-se ao que, em geral, acontece em um serviço de saúde que não opera em um foco de discussão que privilegia essa dimensão "cuidadora", a ponto de influenciar todo o planejamento do serviço. Quando há uma sinalização para isso, não existe uma ênfase na criação de mecanismos para colocar esse foco de discussão na prática do cotidiano do trabalho.

Segundo Merhy ${ }^{9}$, quando não ocorre a dimensão do cuidado nos serviços de saúde, os usuários reclamam da falta de interesse e de responsabilização dos diferentes serviços em torno de si e do seu problema. Os usuários sentem-se inseguros, desinformados, desamparados e desrespeitados. 
Deslandes 12 , ao ressaltar a humanização em oposição à violência, enfatiza a "violência simbólica", que se apresenta como a "dor de não ter a compreensão de suas demandas e suas expectativas", o "não reconhecimento das necessidades emocionais e culturais dos usuários".

Bom. Ótimo [o serviço]. Tem médico que a gente vai, nem fala, não olha nem pra cara da gente, não olha nem pra criança direito. Eu sinto [diferente]. [Aqui] parece que eu estou em casa. (M5)

A confiança que o paciente tem no profissional e no serviço gera uma satisfação e uma resposta melhor daquele paciente diante das orientações profissionais, pois ele passa a participar da consulta. Isto pode ser um mecanismo para enfrentar o desafio da educação em saúde bucal, uma vez que, como destacam Valença13 e Pauleto et al.14, ela é pouco desenvolvida e, quando realizada, está fortemente apoiada em práticas de transmissão de conhecimento, sem espaço para as práticas dialógicas.

Em uma relação profissional/paciente vertical, autoritária e impessoal, não há espaço para uma educação problematizadora, segundo a concepção de Paulo Freire15. Por outro lado, uma relação que privilegia o respeito, a escuta e a responsabilização facilita essa concepção transformadora da realidade, como proposto por Valença ${ }^{13}$, sendo instrumento de um processo de crescimento e tomada de consciência.

Segundo Biato ${ }^{16}$, o aprendizado dos ensinamentos do dentista depende da qualidade da comunicação com o paciente. Deve-se buscar uma escuta atenta e a percepção constante do que o paciente expressa, estabelecendo-se uma conversa de "mão dupla", em que cada um desempenha sua função social.

De acordo com Moraes \& Ongaro'11, no encontro entre o profissional de saúde e o paciente prevalece, geralmente, a representação de papéis sociais estereotipados, no qual o profissional exibe pouca ou nenhuma emoção, procurando manter a neutralidade em sua postura profissional. Já o paciente desempenha um papel passivo e colaborador em relação às intervenções e recomendações do profissional. Entretanto, trata-se de um pensamento reducionista caracterizar a relação que produz cuidado em saúde como uma mera representação desses papéis sociais. Não há dúvida que mesmo um procedimento técnico pode ser fortemente afetado pela qualidade da relação paciente/profissional.

A equipe percebe que os pacientes se sentem valorizados, confiam e têm uma boa relação com os profissionais. Eu acho maravilha, eu gosto muito desse hospital aqui. Se eu tivesse um outro filho, eu gostaria de ter aqui, porque eu fui muito bem atendida. (M3)

Através do contato direto com as famílias, $\mathrm{P} 5$ se preocupa intuitivamente com o aspecto psicossocial e valoriza a história dos pacientes. [...] Eu acho que tem que ficar muito atento ao psicológico, a esse estresse todo. Quem tem responsabilidade com o trabalho.

Para P5, o profissional de saúde da equipe que tem responsabilidade com o trabalho é aquele que valoriza a necessidade de ficar atento ao emocional do paciente. Tal conscientização faz parte do campo de competência e responsabilidade em que se inserem todos os profissionais da equipe, enquanto que a especificidade de cada área profissional é o núcleo de competência e responsabilidade.

Os profissionais da equipe relatam sentir falta de um especialista para tratar do aspecto emocional dos pacientes. [...] psicólogo, com certeza, psicólogo só pro ambulatório, inclusive sendo encaminhados para psicólogo normalmente, porque todos precisam. (P7)

Talvez isso seja, até certo ponto, uma forma de minimizar a capacidade que eles têm de se inserir neste campo de competência e responsabilidade, que inclui o esforço para lidar de uma forma favorável com o psicossocial do usuário.

Nesse contexto, Caprara \& Rodrigues 17 enfatizam que o médico não é estimulado a pensar o paciente como um ser psicossocial, em especial no que se refere a algumas dificuldades, tais como a limitação em lidar com a dinâmica familiar (e suas relações) e com os medos e ansiedades acerca da doença e seus sintomas. Além do suporte técnico-diagnóstico, os médicos necessitam de sensibilidade para conhecer a realidade do paciente, ouvir suas queixas e encontrar, junto com ele, estratégias que facilitem o enfrentamento da doença.

A prática de trabalho de $\mathrm{P} 1$, por exemplo, estabelece uma relação usuário/profissional estendida para o aspecto psicossocial do paciente; e, a partir desta concepção, ela percebe que existem determinados casos de maior complexidade, que necessitam uma atenção especializada. Eu sinto falta de psicólogo, porque nós temos crianças muito problemáticas e a gente acaba não conseguindo dar esse suporte de uma forma adequada [...]. (P1)

Trazendo essa discussão para a saúde bucal, destaca-se um estudo de Drumond18, que buscou aprofundar a compreensão de todos os fa- 
tores relacionados ao surgimento da cárie em crianças, para que o enfrentamento deste problema não fique restrito a ações periféricas. A dimensão sociofamiliar demonstrou que a complexidade dos problemas de relação entre mães e filhos é um fator fundamental para a discussão dos cuidados de saúde bucal com as crianças. Entretanto, o dentista não teria capacidade para trabalhar esse problema por ter uma formação superficial em questões dessa natureza.

Baseando-se nas observações da prática de $\mathrm{P} 5$ e de outros profissionais da equipe, bem como nas transformações no processo de trabalho da dentista dessa equipe, é possível se contrapor às conclusões de Drumond 18 com alguns questionamentos e reflexões. Até que ponto o dentista não tem capacidade para agir, de alguma forma, em relação a esses problemas? A dimensão do cuidado que envolve todos os profissionais de saúde deve trazer uma reflexão sobre como o dentista, enquanto tal, pode agir diante desse quadro. Não seria através da busca constante do vínculo, do acolhimento, da escuta? Não se pretende que o dentista vire psicólogo ou assistente social, até porque estas áreas têm seus próprios núcleos de competência. Entretanto, todos esses profissionais de saúde compartilham o mesmo campo de responsabilidades, que abrange o território das tecnologias leves. Somente imbuído dessa dimensão "viva" do trabalho em saúde é que o dentista irá, de fato, conseguir efetivar uma troca verdadeiramente interdisciplinar com os outros profissionais de saúde (cada qual em seu núcleo específico), para que juntos possam trabalhar as verdadeiras causas dos problemas, e não apenas os seus efeitos.

Moraes \& Ongaro11 relatam que após um período de ênfase no desenvolvimento tecnológico da odontologia e de uma busca pelo conhecimento biológico para a promoção da saúde bucal, surge um terceiro momento da educação odontológica, denominado fase psicossocial. Esta pressupõe que os profissionais da odontologia precisam ser tecnicamente capazes, biologicamente orientados e psicologicamente sensíveis para, desse modo, analisar os fatores psicossociais presentes na relação profissional-paciente.

\section{Considerações finais}

O modo de trabalho do cirurgião-dentista raramente tem se inserido em práticas partilhadas com profissionais de outras áreas, revelando uma escassa familiaridade com o trabalho em equipe. Assim, suas ações ainda permanecem isoladas. Além do mais, são perceptíveis os indícios dessa prática isolada em contextos como o da estrutura dos serviços de saúde - que reforça a divisão do trabalho através de especialidades estanques que pouco interagem - ou nas instituições de ensino e formação do CD, que ainda priorizam o tecnicismo e o biologismo, em detrimento de qualquer possibilidade de integração das disciplinas.

É no trabalho em equipe que existe a possibilidade da troca e do projeto em comum das diversas áreas profissionais envolvidas. A especificidade da odontologia é muito importante e necessária, desde que inserida em um campo comum às várias profissões. Este é o acordo que possibilita o trabalho em equipe em um dado contexto e cotidiano, desde que o dentista não reproduza uma prática isolada, mas passe a atuar em uma perspectiva interdisciplinar, que pressupõe um fator de transformação e de mudança social, como proposto por Fazenda ${ }^{19}$.

Desse modo, existe a possibilidade de inserção nesse campo, no qual entra a produção de vínculo, escuta, acolhimento e responsabilização. Com isso, o trabalho em equipe passa a ser uma forma de multiplicar essa lógica do cuidado nas diferentes áreas profissionais, reconstituindo e alimentando cotidianamente o olhar que cada profissional tem sobre sua prática, o que vale inclusive para as práticas de saúde bucal. 


\section{Agradecimento}

À professora doutora Eliana Miriam Serfaty Gabbay, da Universidade Federal Fluminense, que orientou a minha dissertação de mestrado, parte da qual originou este artigo. Ao professor doutor Marcos Senna, da Universidade Salgado de Oliveira, pela revisão e sugestões.

\section{Referências}

1. Brasil. Ministério da Saúde. HumanizaSUS: Política Nacional de Humanização: documento base para gestores e trabalhadores do SUS. Brasília: MS; 2004.

2. Campos GWS. O anti-Taylor: sobre a invenção de um método para co-governar instituições de saúde produzindo liberdade e compromisso. Cad Saúde Pública 1998; 14(4):863-70.

3. Werneck MAF, Ferreira RC. Tecnologia em saúde bucal. In: Pinto VG, organizador. Saúde bucal coletiva. São Paulo: Santos; 2000. p. 278-91.

4. Merhy EE, Onocko R. Agir em saúde: um desafio para o público. São Paulo: Hucitec; 2002.

5. Minayo MCS. O desafio do conhecimento: pesquisa qualitativa em saúde. 6a ed. São Paulo: Hucitec; Rio de Janeiro: Abrasco; 1999.

6. Japiassu H. Interdisciplinaridade e patologia do saber. Rio de Janeiro: Imago; 1976.

7. Spink MJ, organizador. Práticas discursivas e produção de sentidos no cotidiano: aproximações teóricas e metodológicas. São Paulo: Cortez; 2000.

8. Campos GWS. Subjetividade e administração de pessoal: considerações sobre modos de gerenciar o trabalho em equipes de saúde. In: Merhy EE, Onocko R, organizadores. Agir em saúde: um desafio para o público. São Paulo: Hucitec; 2002. p. 229-66.

9. Merhy EE. Saúde: a cartografia do trabalho vivo. São Paulo: Hucitec; 2002.

10. Aquino BR, Mourão J, Senna MAA, Mocarzel J, H. Barcelos R, Morais AP. O diálogo paciente/profissional na odontologia. Braz Oral Res, Proceedings of the 22nd Annual SBPqO Meeting; 2005 v. 19; São Paulo, Brasil.
11. Moraes ABA, Ongaro S. Contribuição da psicologia da saúde à odontologia. In: Botazzo C, Freitas STF, organizadores. Ciências sociais e saúde bucal: questões e perspectivas. São Paulo: Edusc; 1998. p. 87-103.

12. Deslandes SF. Análise do discurso oficial sobre a humanização da assistência hospitalar. Rev C S Col 2004; 9(1):7-14.

13. Valença AMG. A educação em saúde na formação do cirurgião-dentista: da necessidade à prática participativa. Niterói: EdUFF; 1998.

14. Pauleto ARC, Pereira MLT, Cyrino EG. Saúde bucal: uma revisão crítica sobre programações educativas para escolares. Rev C S Col 2004; 9(1):121-30.

15. Freire P. Pedagogia do oprimido. Rio de Janeiro: Paz e Terra; 1975.

16. Biato ECL. Processos educativos no campo da saúde: a atuação do profissional de odontologia junto a pacientes especiais [dissertação]. Piracicaba (SP): Faculdade de Ciências Humanas da Universidade Metodista de Piracicaba; 2003.

17. Caprara A, Rodrigues J. A relação assimétrica médico-paciente: repensando o vínculo terapêutico. Rev $C$ $S$ Col 2004; 9(1):139-46.

18. Drumond MM. A criança, seu "em torno" e a cárie [tese]. Niterói: Universidade Federal Fluminense; 2002.

19. Fazenda ICA. Interdisciplinaridade: história, teoria e pesquisa. Campinas: Papirus; 1995.

Artigo apresentado em 13/05/2005

Aprovado em 30/08/2005

Versão final apresentada em 17/11/2005 